\title{
Comparison of 3D laser-based photonic scans and manual anthropometric measurements of body size and shape in a validation study of 123 young Swiss men
}

\author{
Nikola Koepke ${ }^{\text {Corresp., }}{ }^{1}$, Marcel Zwahlen ${ }^{2}$, Jonathan C Wells ${ }^{3}$ ， Nicole Bender ${ }^{1}$ ， Maciej Henneberg ${ }^{1,4}$, Frank J \\ Rühli ${ }^{1}$, Kaspar Staub ${ }^{\text {Corresp. } 1}$ \\ 1 Institute of Evolutionary Medicine, University of Zurich, Zurich, Switzerland \\ 2 Institute of Social and Preventive Medicine, University of Bern, Bern, Switzerland \\ 3 Institute of Child Health / Childhood Nutrition Research Centre, University College London, London, United Kingdom \\ 4 Adelaide Medical School, University of Adelaide, Adelaide, South Australia, Australia \\ Corresponding Authors: Nikola Koepke, Kaspar Staub \\ Email address: nikola.koepke@uzh.ch, kaspar.staub@iem.uzh.ch
}

Background: Manual anthropometric measurements are time-consuming and challenging to perform within acceptable intra- and inter-individual error margins in large studies. Three-dimensional (3D) laser body scanners provide a fast and precise alternative: Within a few seconds the system produces a 3D image of the body topography and calculates some 150 standardised body size measurements.

Objective: The aim was to enhance the small number of existing validation studies and compare scan and manual techniques based on five selected measurements. We assessed the agreement between two repeated measurements within the two methods, analysed the direct agreement between the two methods, and explored the differences between the techniques when used in regressions assessing the effect of health related determinants on body shape indices.

Methods: We performed two repeated body scans on 123 volunteering young men using a Vitus Smart XXL body scanner. We manually measured height, waist, hip, buttock, and chest circumferences twice for each participant according to the WHO guidelines. The participants also filled in a basic questionnaire.

Results: Mean differences between the two scan measurements were smaller than between the two manual measurements, and precision and intra-class correlation coefficients were higher. Both techniques were strongly correlated. When comparing means between both techniques we found significant differences: Height was systematically shorter by $2.1 \mathrm{~cm}$, whereas waist, hip and bust circumference measurements were larger in the scans by $1.17-4.37 \mathrm{~cm}$. In consequence, body shape indices also became larger and the prevalence of overweight was greater when calculated from the scans. Between $4.1 \%$ and $7.3 \%$ of the probands changed risk category from normal to overweight when classified based on the scans. However, when employing regression analyses the two measurement techniques resulted in very similar coefficients, confidence intervals, and p-values.

Conclusion: For performing a large number of measurements in a large group of probands in a short time, body scans generally showed good feasibility, reliability, and validity in comparison to manual measurements. The systematic differences between the methods may result from their technical nature (contact vs. non-contact). 
1 Comparison of 3D laser-based photonic scans and manual

2 anthropometric measurements of body size and shape in a

3 validation study of 123 young Swiss men

4 Nikola Koepke ${ }^{1}$, Marcel Zwahlen ${ }^{2}$, Jonathan CK Wells ${ }^{3}$, Nicole Bender ${ }^{1}$, Maciej Henneberg ${ }^{1,4}$,

5 Frank J Rühli ${ }^{1 *}$, Kaspar Staub $^{1 *}$

$6{ }^{1}$ Institute of Evolutionary Medicine, University of Zurich, Zurich, Switzerland

$7 \quad 2$ Institute of Social and Preventive Medicine, University of Bern, Bern, Switzerland

$8{ }^{3}$ Childhood Nutrition Research Centre, UCL Institute of Child Health, London, United Kingdom

$9{ }^{4}$ Medical School, University of Adelaide, Australia

$10 *$ These authors contributed equally to this work: last authorship

11 Corresponding Author: Nikola Koepke, Kaspar Staub

12 E-mail address: nikola.koepke@uzh.ch, kaspar.staub@iem.uzh.ch 
13 Abstract

14 Background: Manual anthropometric measurements are time-consuming and challenging to perform within acceptable intra- and inter-individual error margins in large studies. Threedimensional (3D) laser body scanners provide a fast and precise alternative: Within a few seconds the system produces a 3D image of the body topography and calculates some 150 standardised body size measurements.

Objective: The aim was to enhance the small number of existing validation studies and compare scan and manual techniques based on five selected measurements. We assessed the agreement between two repeated measurements within the two methods, analysed the direct agreement between the two methods, and explored the differences between the techniques when used in regressions assessing the effect of health related determinants on body shape indices.

Methods: We performed two repeated body scans on 123 volunteering young men using a Vitus Smart XXL body scanner. We manually measured height, waist, hip, buttock, and chest circumferences twice for each participant according to the WHO guidelines. The participants also filled in a basic questionnaire.

Results: Mean differences between the two scan measurements were smaller than between the two manual measurements, and precision and intra-class correlation coefficients were higher. Both techniques were strongly correlated. When comparing means between both techniques we found significant differences: Height was systematically shorter by $2.1 \mathrm{~cm}$, whereas waist, hip and bust circumference measurements were larger in the scans by $1.17-4.37 \mathrm{~cm}$. In consequence, body shape indices also became larger and the prevalence of overweight was greater when calculated from the scans. Between $4.1 \%$ and $7.3 \%$ of the probands changed risk category from normal to overweight when classified based on the scans. However, when employing regression analyses the two measurement techniques resulted in very similar coefficients, confidence intervals, and p-values.

Conclusion: For performing a large number of measurements in a large group of probands in a short time, body scans generally showed good feasibility, reliability, and validity in comparison 
40

41

42

to manual measurements. The systematic differences between the methods may result from their technical nature (contact vs. non-contact).

\section{Introduction}

Body size and shape are directly linked to human health: being both underweight or overweight/obese is associated with increased morbidity and mortality risks (Engeland et al., 2003; WHO, 2009; Faeh, Braun \& Bopp, 2012; Flegal et al., 2013; Kit, Ogden \& Flegal, 2014). The prevalence of overweight and obesity $(\mathrm{OW} / \mathrm{OB})$ is still on the rise worldwide (NCD-RisC, 2016). Switzerland is no exception; OW/OB numbers have increased since the 1990 s with significant variation by sex, age, region, migration status, and/or socio-economic background (Faeh, Braun \& Bopp, 2012). Monitoring OW/OB on the population and/or individual level and identifying groups at risk is essential to plan public health interventions in order to reduce future health and economic burdens at the societal level (Schmid et al., 2005; Schneider et al., 2010; Davin et al., 2012; Schneider \& Venetz, 2014).

Adipose tissue distribution has proven to be particularly important regarding the health risks associated with $\mathrm{OW} / \mathrm{OB}$. It is particularly abdominal fat that has adverse outcomes (cardiovascular diseases, type 2 diabetes, cancer, metabolic syndrome) (Yusuf et al., 2005; Pischon et al., 2008; Gracia-Marco et al., 2016). The standard imaging methods used to precisely assess body composition and fat distribution (MRI, DEXA, CT) are either invasive or timeconsuming, and expensive, and thus not suitable for large-scale monitoring studies (Machann et al., 2005; Lee \& Gallagher, 2008). A cheaper and faster way is the external assessment of body size and shape by standard anthropometric measurements using hand-held tape measures, callipers, and stadiometer, which are traditionally used in larger epidemiological studies (Preedy, 2012; Malatesta, 2013). 
68

69

percentage of body fat on the population level, there are exceptions and misclassifications at the individual level (most notably athletes) (Marques-Vidal et al., 2008; Schneider et al., 2010). Body shape indices, such as waist circumference (WC), waist-to-hip-ratio (WHR), or waist-to-heightratio (WHtR) are recently gaining importance because of their improved indication of abdominal fat (Ashwell \& Hsieh, 2005; Yusuf et al., 2005; Ogna et al., 2014). Even when standardising guidelines and operation procedures (on posture, breathing position, tape-positioning, and tapetension) exist and the measurements are performed by trained and experienced personnel, obtaining reliable, precise, and accurate manual waist and hip circumference is time-consuming in larger samples and challenging to perform within acceptable intra- and inter-individual errors (Higgins, 2012; Verweij et al., 2013).

Recently, 3D photonic surface scans rapidly emerged as an attractive digital alternative to anthropometrically assessed body size and shape (Lin et al., 2004; Olivares et al., 2007; Treleaven \& Wells, 2007; Veitch, Veitch \& Henneberg, 2007; Wells et al., 2008; Bretschneider et al., 2009; Wells, 2012; Olds et al., 2013; Jaeschke, Steinbrecher \& Pischon, 2015; Loeffler et al., 2015; Peyer, Morris \& Sellers, 2015; Wells et al., 2015; Kuehnapfel et al., 2016). Within only 1215 seconds the system scans the body surface; software algorithms then produce a 3D image of the body topography (consisting of 700,000 to one million individual data points in the 3D space), a large number of landmarks are automatically located by the software, and ca. 150 standard body size measurements are calculated from these scan landmarks (Wells, 2012). The advantage of 3D technology lies in the large number of measurements taken in a very short time, the improved standardisation due to the reduced physical contact between observers and probands (by eliminating potential error sources such as tape-tension, etc.), the possibility to adjust or take additional measurements (or composite new models for body shape) from the virtual body, and the electronic archiving of the 3D images for reassessment and individual follow-ups with improved software (Wells et al., 2015). There are even some studies showing that 3-D body scan results correlate with total and regional fat mass (Wang et al., 2006; Lee et al., 2015a; Lee et al., 2015b; $\mathrm{Ng}$ et al., 2016), but further evidence is needed as to whether they can produce reliable predictions when compared to DEXA or MRI standards.

Thus, the scan technique - originally developed for the clothing industry - allows the comprehensive measurement of body shape in a large number of individuals in a short time (Wells et al., 2015). Consequently, its application in larger epidemiological studies on adults and 
99 children is currently gaining importance. A small number of recent validation studies comparing

100 the scan technique with manual measurements (e.g., waist or hip circumferences) have shown the

101 applicability of the scan technique in an epidemiological setting (Wells, Treleaven \&

102 Charoensiriwath, 2011; Jaeschke, Steinbrecher \& Pischon, 2015; Loeffler et al., 2015;

103 Kuehnapfel et al., 2016), using the same device as the one studied here. The scans generally

104 showed good feasibility, reliability, and validity; correlations to parameters of the metabolic

105 syndrome were similar to those of manual measurements (Jaeschke, Steinbrecher \& Pischon,

106 2015). Scan and manual data showed generally a high level of ranking consistency and

107 correlation between methods, but there are also indications for systematic bias (the scans provide

108 slightly larger values than the manual measurements) (Wang et al., 2006; Heuberger, Domina \&

109 MacGillivray, 2008; Choi \& Ashdown, 2011; Jaeschke, Steinbrecher \& Pischon, 2015). Because

110 there are different types of scanner hardware available, and also different ways through which

111 software processes raw data to give final outputs, it is worth contributing additional validation 112 studies.

113 The aim of this study was to compare the scanning and the manual anthropometric measurement 114 techniques based on five selected body measurements (height, waist, hip, buttock, and chest 115 circumferences) to add to the still small number of reliability and validation studies with the aim 116 to further implement this method in population-based studies.

\section{2. Data and methods}

\section{Study sample}

119 The cross-sectional study was conducted in February 2013 on Irchel Campus of the University of Zurich. We collected scanned and manually measured anthropometric as well as questionnaire data on simple health-related aspects of 127 young adult males, voluntarily recruited via public advertisement (flyers, internet, social media, radio, oral communication, etc.) in the university environment. We assume that most of the probands were university students but we did not ask for occupation in the questionnaire. We exclusively focussed on young males because one of the future application of the technique will be among male Swiss Armed Forces conscripts. We 
127 to incomplete data. The remaining study sample $(\mathrm{N}=123)$ was between 18 to 38 years old (mean age $=24.55$ years, $\mathrm{SD}=4.18)$, with 15 men $(12.2 \%)$ being $>=30$ years (Table 1). The study sample included both, young men not regularly performing sports $(34.2 \%<2.5$ hours per week) and sportive young men (35.8\% regularly performed $>=5.0$ hours of sports per week). The number of participants with three or more visits to a physician during the last year was rather low (15.5\%), which indicates that most of the study probands were in good general health. Overall, the participants covered a wide spectrum of existing body shape variation in young men (Figure 1). The low-quality raw scan outputs show the thinnest (scanned BMI $=16.85 \mathrm{~kg} / \mathrm{m} 2$ ) and the heaviest $(\mathrm{BMI}=29.48 \mathrm{~kg} / \mathrm{m} 2)$ participant, as well as exemplary two participants, whose BMI was similar $\left(27.94 \mathrm{vs} .27 .73 \mathrm{~kg} / \mathrm{m}^{2}\right)$, but in contrast to subject 37 subject 30 represented the more athletic body shape type (reporting 17 hours of sport per week).

\section{Data collection}

The participants underwent three measurement steps in separate rooms within a total maximum time of 20 minutes each: a) filling in a basic questionnaire, b) scan measurements (scans), and c) manual measurements (hand/tape measurements).

\section{a) Questionnaire data}

In the first step, the participants filled in a basic questionnaire about their age (rounded to full years), their current physical activity level (expressed as total hours of sports per week), and the number of visits to a physician during the last year (as a crude proxy for their health status)

\section{(Table 1).}

\section{b) Scan measurements}

In the second step, scan measurements ( $\mathrm{SM}=3 \mathrm{D}$ body scans) were performed on the participants using a mobile Body Scanner Vitus Smart XXL and the software AnthroScan Professional (both from Human Solutions GmbH, Kaiserslautern, Germany), both integrated into a converted truck (the scanliner) of the Swiss Armed Forces Logistics Organisation (Armasuisse). This device is currently successfully used in different epidemiological studies in Germany (Bretschneider et al., 2009; Jaeschke, Steinbrecher \& Pischon, 2015; Loeffler et al., 2015; Kuehnapfel et al., 2016). Each participant was subsequently scanned twice (scan measurements 1 and 2: SM1 and SM2). The participants wore form-fitting underpants only (without shoes) and a tight-fitting bathing cap. 
156 The scans were performed by the study authors together with experienced Armasuisse scan 157 operators. The scanner was calibrated once at the beginning of every measurement day following 158 official protocols of the manufacturer. The participants were asked to hold their breath in an 159 exhaled status and stand in the standard position defined by the manufacturer (standing upright, 160 relaxed, on a marker setting, legs hip-wide apart, upper limbs slightly bend at the elbows and held 161 away from the body, head positioned in accordance with the Frankfurt Horizontal Plane). Instructions for positioning on the scanner platform were repeated prior to each scan. The scans were immediately inspected visually for their quality, and had to be repeated in four out of a total of 254 scans (mostly due to twisted topography in the head area caused by movement during the scan procedure). Using four eye-safe lasers and eight cameras, the 3D-scanner provides a point cloud of about 1 million data points, based on optical triangulation. In the standard setting, 154 digital outcomes were determined by the software according to ISO 20685:2005 (ISO, 2005). In order to focus on the shape of the trunk (and this abdominal fat) in future studies, we chose body height and four circumference measurements of the trunk area to compare with the manual measurements. According to the operating scan protocol of the manufacturer (automatic landmark positioning), we chose the scan measurements "waist girth", "hip girth", "buttock girth", and "chest girth" (across the bust point landmarks at the level of the nipples) to compare the scan technique with the traditional manual measurements.

\section{c) Manual measurements}

175 During the third examination step each participant was manually measured twice by two different trained anthropometrists. In $\mathrm{N}=1$ no measurement could be conducted. The participants wore form-fitting underpants only (without shoes) and stood upright with arms at the sides, feet positioned close together, and weight evenly distributed across the feet. We measured height, waist circumference, hip circumference, buttock circumference, and bust circumference twice for each participant (manual measurements 1 and 2: MM1 and MM2). Height was measured by a standard stadiometer (seca 216, fixed at the wall and regularly calibrated/controlled during the measurement period). For the circumference measurements a standard stretch-resistant hand-held tape was used and measurements were taken at the end of normal expiration, with the tape parallel to the floor (according to the official measurement protocols in use): Waist circumference was measured at the approximate midpoint between the lower margin of the last palpable rib and the top of the iliac crest (WHO, 2008). Hip circumference was measured around the widest 
188 buttock curve (NHANES, 1988). Chest circumference was measured at the level of the papilla of

189 the breast. In addition, the participants (wearing form-fitting underpants only) were weighed once

190 to the nearest $0.1 \mathrm{~kg}$ with a standard medical weight scale (SECA 877 digital scale, Hamburg,

191 Germany) during step c).

192 Body shape indices

193 Based on the mean of the two scans $(\mathrm{mSM}=(\mathrm{SM} 1+\mathrm{SM} 2) / 2)$ and the mean of the two manual $194(\mathrm{mMM}=(\mathrm{MM} 1+\mathrm{MM} 2) / 2)$ measurements we calculated the most commonly used indices for body 195 shape and abdominal fat distribution for each of the two techniques: BMI (= weight $(\mathrm{kg}) /($ height $196\left(\mathrm{~m}^{2}\right)$ ), WHR (= waist circumference / hip circumference), and WHtR (= waist circumference / 197 height). In a next step, the participants were assigned to the official WHO risk categories for 198 OW/OB for each of the indices and the two techniques (Schneider et al., 2010; WHO, 2014).

\section{Statistical methods}

200 First, we assessed the agreement between two repeated measurements within the two methods. To test the repeatability and the agreement between the repeated measurements within each of the two methods (SM1-SM2 and MM1-MM2) we calculated mean differences, intraclass correlation coefficients (ICC), precision (calculated based on the square root of the sum of squared differences between measurements divided by the number of observations) (Altman, 1999), and paired t-tests for two samples. For the direct comparison between scan and manual measurements we used the mean scan measurement (mSM) and the mean manual measurement (mMM). Second, we analysed the direct agreement between scan and manual measurements for each of the selected measurements and for the resultant body shape indices to control for potential systematic differences. We calculated mean differences (mSM-mMM), correlation coefficients, and paired t-tests for two samples. Furthermore, we also performed Lin's concordance correlation coefficient (CCC) (Lin, 1989): it is calculated as CCC $=r * C_{-} b$, where $r$ is the Pearson correlation coefficient and $\mathrm{C}_{-} \mathrm{b}$ is a bias correction factor. The $\mathrm{r}$ variable evaluates precision, whereas $\mathrm{C} \_$b evaluates accuracy concerning the degree to which measures deviate from the bestfit line. Visual inspection was done via scatterplots, kernel density plots, and the Bland-Altman

215 (BA) method (Bland \& Altman, 1986, 1999) for both intra- and inter-method comparisons. The BA method analyses the paired difference as a function of the average of the paired measurements. This is first done by graphical displays of the difference between the methods 
218 against their mean, then by calculating the mean difference and the standard deviation of the

219 differences, which defines a range of agreement (Jaeschke, Steinbrecher \& Pischon, 2015; Wells

220 et al., 2015). For the calculated body shape indices WC, WHR, and WHtR, we computed mean

221 differences (mSM-mMM), Pearson correlation coefficients, Lin's concordance correlation

222 coefficient (CCC), and paired t-tests for two samples to test the agreement between scan and

223 manual measurements. Reclassification between the official OW/OB categories when comparing

224 the two methods was assessed by percentages in relation to the total sample and agreement by

225 calculating kappa coefficients (Altman, 1999): Kappa was assessed according to Altman's

226 reference range: $0.41-0.60=$ moderate agreement; $0.61-0.80=$ good agreement, $>0.80=$

227 excellent agreement.

228 Third, to assess if the two techniques result in similar results and coefficients when analysing

229 sub-group differences, regression models testing health-related determinants of body shape

230 indices based on questionnaire answers, we performed linear regressions with WC, WHR, and

231 WHtR as dependent variables and categorised age, total hours of sports per week, and number of

232 visits to a physician during the last year as independent variables. We used SPSS23 and Stata14

233 for all analyses.

\section{Ethics statement}

235 All of the young men participated voluntarily in this study. They were informed in detail by the 236 study leaders about the study (aim, protocol, risks, etc.) in written form prior to the measurement

237 days and once again orally at the beginning of their measurements by the study leaders. Prior to 238 the start of the measurements all participants signed a detailed informed consent form. At the 239 time of measurement (February 2013) a waiver by the ethics committee of the Canton of Zurich 240 was not needed for such non-clinical and non-invasive studies.

\section{3. Results}

\section{Agreement between the repeated measurements within methods}

243 Agreement between the two repeated measurements within the two methods is reported in Table

244 2. The mean differences between the two scan measurements (SM1-SM2) were the smallest for 
245 height $(-0.04 \mathrm{~cm})$ and the largest for chest and buttock circumferences $(0.11 \mathrm{~cm})$. The ICC was

246 smaller than 0.993 only in the case of chest circumference (0.981) and precision was below

$2471.24 \mathrm{~cm}$ for all SM. The paired t-tests for two samples resulted in non-significant $\mathrm{p}$-values in all

248 five measurements. The mean difference between the two manual measurements (MM1-MM2)

249 was again the lowest (and non-significant) for height $(0.05 \mathrm{~cm})$ but significantly larger than

$250-0.23 \mathrm{~cm}$ and up to $-0.75 \mathrm{~cm}$ in all other manual measurements. The ICC between the two manual

251 measurements was greater than 0.991 only in the case of height (0.999). Precision was higher

252 than $2.50 \mathrm{~cm}$ and up to $8.19 \mathrm{~cm}$ in all manual measurements (indicating greater disagreement).

253 Only in the case of height, the two manual measurements produced similarly low disagreeing

254 results as the two repeated scan measurements $(-0.04 \mathrm{~cm}$ vs. $0.05 \mathrm{~cm}$ mean difference, $0.998 \mathrm{vs}$.

2550.999 ICC, 0.45 vs. $0.50 \mathrm{~cm}$ precision). The kernel density plots and BA plots confirm the

256 generally closer agreement and higher reliability between the two scans than between the two

257 manual measurements in the other four analysed measures (chest, waist, hip and buttock

258 circumference) (Appendix Figure 1).

259 Agreement between methods: scan versus manual measurements

260 For the direct comparison between scan and manual measurements we calculated the mean of

261 each of the two basic measurements, the mean scan measurement $(\mathrm{mSM}=(\mathrm{SM} 1+\mathrm{SM} 2) / 2)$ and the

262 mean manual measurement $(\mathrm{mMM}=(\mathrm{MM} 1+\mathrm{MM} 2) / 2)$. Overall, correlation between $\mathrm{mSM}$ and

$263 \mathrm{mMM}$ values was high $(\mathrm{r}>=0.93)$, except in the case of the buttock circumference $(\mathrm{r}=0.83)$ (Table

264 3). When calculating, Lin's concordance correlation coefficient (CCC), which adjusts Pearson's $r$

265 by a bias correction factor, CCC remains high $(>0.94)$ for height and waist circumference. For

266 chest circumference, CCC was still 0.781 for hip circumference and 0.784 for chest

267 circumference. For buttock circumference C_b was only 0.312 , which resulted in a low CCC of

2680.258 (Table 3). However, comparing mean levels revealed significant differences between mSM

269 and mMM. In the case of height, $\mathrm{mSM}(178.31 \mathrm{~cm}, \mathrm{SD}=6.51)$ was significantly shorter than

$270 \mathrm{mMM}(180.32 \mathrm{~cm}, \mathrm{SD}=6.54)$ by $-2.01 \mathrm{~cm}(\mathrm{SD}=0.77, \mathrm{p}<0.001)$. In contrast, $\mathrm{mSM}$ was

271 significantly larger than mMM in all analysed circumference measurements. The difference was

272 the smallest for waist circumference $(+1.17 \mathrm{~cm}, \mathrm{SD}=0.13)$ and the largest for buttock

273 circumference $(+12.62 \mathrm{~cm}, \mathrm{SD}=0.35)$. For chest and hip circumference the difference was in the

274 expected range of approximately $4 \mathrm{~cm}$, with $+3.88 \mathrm{~cm}(\mathrm{SD}=2.17)$ for chest and $+4.37 \mathrm{~cm}$

$275(\mathrm{SD}=0.19)$ for hip. The scatterplots, kernel density plots, and BA plots in Figure 2 confirm the 
276 observed pattern: $\mathrm{mSM}$ were smaller than $\mathrm{mMM}$ for height and larger for the four circumference

277 measures (chest, waist, hip, buttock). The kernel density plots further show that although the

278 position of the distributions on the $\mathrm{x}$-axis differed, their shape was consistently similar between

$279 \mathrm{mSM}$ and mMM.

280

281

282

\section{Body shape indices: agreement between scan and manual measurements}

We also tested the agreement between the two methods when using mSM and mMM to calculate the most commonly used indices of body shape -WC, WHR, WHtR, BMI - and when assigning the subjects to the official WHO categories regarding the linked health risk. The results for waist circumference (WC) are reported in the previous section. The correlation coefficients were very high (0.98. and 0.99) for WHtR and BMI, but lower (0.85) for WHR (Table 3). The concordance correlation coefficients (CCC) were high $(>0.92)$ for WHtR and BMI, whereas the lower accuracy measure $C_{-} b=0.786$ for WHR resulted in lower CCC of 0.673 . The mean difference was $-0.03(\mathrm{SD}=0.002)$ for WHR. The scanned WHtR were on average $0.01(\mathrm{SD}=0.001)$ higher than the manual measured WHtR, reflecting the larger circumference and smaller height measurements when scanning the individuals. BMI calculated by $\mathrm{mSM}$ was $0.52 \mathrm{~kg} / \mathrm{m}^{2}(\mathrm{SD}=0.21)$ higher than calculated by mMM (caused by the lower mSM values for height taken from the scans). The paired t-test revealed significant $(\mathrm{p}<0.001)$ differences between $\mathrm{mSM}$ and $\mathrm{mMM}$ for all body shape indices.

Regardless of the applied method and the calculated body shape index, none of the measured subjects reached the highest risk-related WHO-category of being obese $(\mathrm{WC} \geq 102.0 \mathrm{~cm}$, WHR $\geq 1.0$, and $B M I \geq 30.0 \mathrm{~kg} / \mathrm{m}^{2}$ ) (Table 4). However, there were differences in the prevalence of overweight between $\mathrm{mSM}$ and mMM based calculations within each of the four body shape indices, on the one hand, and between the four body shape indices within one applied method on the other hand. For WC, the prevalence of overweight $(94.0-101.0 \mathrm{~cm})$ was $4.0 \%$ greater $(\mathrm{N}=5$ out of 123 subjects more) when calculated based on the scans compared to the manual measurements (7.3\% vs. 3.3\%). Thus, five out of 123 subjects changed from the normal category to the category under risk. For WHR, the differences in the prevalence of overweight (0.9-1.0) between mSMand $\mathrm{mMM}$-based ratios was the smallest $(-1.6 \%$ or $\mathrm{N}=2)$ among all body shape indices $(5.7 \%$ for $\mathrm{mSM}$ vs. $7.3 \%$ for $\mathrm{mMM}$ ). When also taking height and not only circumference measurements into account by calculating WHtR and BMI, the prevalence of overweight increased. For WHtR, 
$30614.8 \%$ were overweight (WHtR $\geq 0.5$ ) for $\mathrm{mSM}$ compared to $9.8 \%$ for $\mathrm{mMM}$ (difference $=4.8 \%$ or $307 \mathrm{~N}=6)$. For BMI, $22.8 \%$ were overweight $\left(25.0-29.9 \mathrm{~kg} / \mathrm{m}^{2}\right)$ for $\mathrm{mSM}$ compared to $15.4 \%$ for $308 \mathrm{mMM}$ (difference $=7.4 \%$ or $\mathrm{N}=9$ ). Kappa coefficients between scans and manual measurements 309 showed moderate agreement for WHtR (0.58) and WC (0.60), substantial agreement for BMI 310 (0.76), and almost perfect agreement for WHR (0.87).

\section{Comparing techniques in sub-group analysis regressions}

312 When estimating the associations of sports hours per week, number of visits to a physician during 313 the last year, and age with WC, WHR, WHtR, and BMI we found no significant results for sports 314 hours and visits to a physician (Figure 3 and Appendix Table 1). However, there was a non315 significant tendency to lower WC, WHR, and WHtR values among the men performing $316 \geq 7.5$ hours of sports per week. The strongest, but only partially significant association, was found 317 for age, with a tendency for higher values in all body shape indices for men older than 30 years. 318 In general, the performed regressions resulted in very similar coefficients, confidence intervals, 319 and p-values among the sub-groups for both, the scan and the manual techniques.

\section{Discussion}

We successfully performed repeated body scans and manual measurements on 123 individuals. We found that the mean differences within the two scan measurements were smaller than within the two manual measurements, and correspondingly precision and intraclass correlation coefficients were higher. We also found both techniques to be highly correlated. Nevertheless, when comparing means between both techniques we found significant differences: Height was systematically shorter in the scans, whereas all four circumference measurements taken from the trunk and hip were larger in the scans. In consequence, body shape indices WC, WHtR, and BMI also became significantly larger and, correspondingly, the prevalence of overweight was greater when calculated from the scans. Depending on the index, between $4.1 \%$ and $7.3 \%$ of the probands ( $\mathrm{N}=5$ to 9 men out of 123 ) changed the risk category from normal to overweight when classified based on the scans measurements. However, when employing regression analyses the two measurement techniques resulted in very similar coefficients, confidence intervals, and pvalues. 
334 The better precision and repeatability within repeated scan measurements was also found by

335

336

337

338

339

340

341

342

343

344

345

346

347 earlier validation studies on adult probands (Heuberger, Domina \& MacGillivray, 2008; Verweij et al., 2013; Jaeschke, Steinbrecher \& Pischon, 2015; Sebo et al., 2015) and can at least partially be explained by generally reduced inter- and intra-observer variance. On the one hand, measurement protocols (automatic landmark identification) are more standardised in the scans. On the other hand, the classical manual anthropometric measurements bear more potential for intra- and inter-observer errors in terms of tape-positioning and -tightening, etc. (WHO, 2008). This is also reflected in the more differing appearance of the kernel density plots when comparing two manual circumference measurements against each other in Appendix Figure 2. In particular, manually measuring buttock circumference was subject to larger inter-observer errors in our study. Only height measurements were equally precise in both of the applied techniques. The linear nature of manual height measurement by the means of a fixed stadiometer presumably allows better repeatability (in contrast to tape-measured circumferences).

That height was systematically shorter in the scans than when manually measured conflicts with some of the existing earlier validation studies: In these studies, the larger height values in the scans are explained by issues related to the worn bathing cap (air beneath, or lots of hair upbiasing height) (Han, Nam \& Choi, 2010; Jaeschke, Steinbrecher \& Pischon, 2015; Psikuta et al., 2015; Kuehnapfel et al., 2016). However, our contrary finding could be explained by the following hypothetical factors: In the scanner, participants are standing with the legs hip-wide apart (to enable the scanner/software to correctly identify the crotch), while they are standing with legs closer together when being manually measured (WHO, 2008). Furthermore, the physical contact between the back of the body and the stadiometer in the manual measurement could keep the body posture straight and elongated at the back. In contrast, the probands tend to slightly deviate from the Frankfurt Plane and bend forward in the scans, possibly resulting in a reduced height. We calibrated and controlled our stadiometer several times during the measuring days to eliminate possible confounding technical measurement errors. However, future studies should test these potentially biasing factors.

Our finding that waist, hip, and buttock circumferences were systematically larger in scans than manually measured finds broad support in other validation studies (Han, Nam \& Choi, 2010; Choi \& Ashdown, 2011; Jaeschke, Steinbrecher \& Pischon, 2015; Ng et al., 2016). The mean differences we found for the present study were relatively small for waist circumference 
$365(+1.2 \mathrm{~cm})$, and in the expected range of plus $3-5 \mathrm{~cm}$ for hip and chest circumference. When 366 measured manually, the physical contact and proximity to the measurer might influence body 367 posture and contraction of the trunk area of the probands resulting in smaller values (Jaeschke, 368 Steinbrecher \& Pischon, 2015). In the case of hip circumference, the standard scanning posture 369 with legs hip-width apart might enlarge the resulting measurements (McKinnon \& Istook, 2002). 370 In general, the hand-held tape measurements have a tendency to compress the circumference 371 caused by too much tension and, thus, reduce the values (Wang et al., 2006). Lastly, the non372 automatic positioning of the tape in manual measurements is challenging, even when conducted 373 by trained personnel, which possibly also results in greater variation. In our study, the largest mean difference of $12.6 \mathrm{~cm}$ was found for buttock circumference. This unreliably large deviation originates from an unintended inconsistency of measurement positioning between the two techniques: Whereas the scanner measured the largest circumference around the buttock, the manual measurers measured the circumference on the mid-buttock position. This error between protocols highlights the importance to carefully synchronise the manual and scan measurement landmarks.

The smaller height and the larger waist circumference measurements in the scans resulted in higher BMI, WC, and WHtR values. For WHR, the systematically greater hip circumference resulted in lower values in the scans. As a consequence, re-classification between the risk categories may become an issue, and the impact on related health outcomes has to be addressed by further studies. However, our data showed relatively low re-classification percentages of $4.1 \%$ to $7.3 \%$ and generally moderate to excellent Kappa agreement results between techniques and risk categories.

Regarding the performed regressions, we found no influence of physical activity or numbers of visits to a physician on all four tested body shape indices, irrespective of the applied technique. However, we found a non-significant tendency to larger body shape with increasing age (again for both techniques), generally reflecting weight-gain with increasing age (Bogin, 1999; Mason \& Katzmarzyk, 2009). More importantly, the two measurement techniques resulted in very similar coefficients, confidence intervals, and p-values for the tested sub-groups of age, physical activity, and visits to a physician. This underlines the findings of an earlier study indicating that the two techniques, despite of systematic differences, showed similar correlations to parameters of the metabolic syndrome (Jaeschke, Steinbrecher \& Pischon, 2015). 
396 This study has several limitations: First, the studied young men are not representative for the

397 general Swiss population. We did not include women and older age groups, who might show

398 deviating differences between the manual and scanned measurements. Randomisation might

399 furthermore be affected due to the voluntary participation of the probands, which presumably

400 resulted in a lower than average prevalence of overweight and obese individuals in the sample. In

401 particular, the differences between the two techniques might be larger in obese individuals, even

402 when a recent validation study (Kuehnapfel et al., 2016) did not find significant diverging

403 applicability results for obese probands. On the one side, the homogeneous composition of our

404 relatively large sample allowed for a comparison of the two techniques without possibly biasing

405 body shape extremes (very short/tall or obese probands can affect the variability of tape

406 measurements (Gibson, 2005)). On the other side, epidemiological studies often cover a wide

407 variability of body shapes. To enhance the representativeness such validation studies should rely

408 on samples with greater heterogeneity and also include obese individuals. Second, the applied

409 questionnaire was limited in its explanatory power. In the non-clinical setting of our study we

410 were not allowed to collect more detailed health information or even measure parameters of the

411 metabolic syndrome. However, testing determinants of body shape was not the main interest of

412 this study, as we aimed at comparing the two techniques upon differences in the effect size of

413 selected determinants. Third, anthropometric measures are also influenced by the time of the day

414 (e.g., being taller in the morning than in the evening) or the training level of the measurers. We

415 made an effort to reduce these possible sources of error by taking scans and manual

416 measurements isochronally within 20 minutes for each participant and by additionally briefing

417 the experienced medical measurers to strictly stick to the protocols (Sebo et al., 2015). Fourth, we

418 did not have access to the software algorithms calculating the $3 \mathrm{D}$ virtual body and consecutively

419 the measurements from it. As for earlier validation studies, these algorithms were not accessible

420 (Kuehnapfel et al., 2016) and could not be controlled for their possible influence on the results of

421 this study. Fifth, we only compared five selected of the over 150 available standard scan

422 measurements with their manual equivalent. However, other studies have shown the validity of

423 the scans also for other standard measurements, even when particular body areas such as the top

424 of the shoulders or the neck area are more difficult to assess by the scans (Daniell, Olds \&

425 Tomkinson, 2012; Tomkinson \& Shaw, 2013). 
426 Our study highlights the strengths and limitations regarding the use of 3D technology in large427 scale surveys intended to categorise nutritional status for public health ends, as opposed to 428 obtaining data for the retail industry, which has been the main purpose of large 3D surveys to 429 date. The high correlations between 3D and manual measurements indicate that 3D technology is 430 very successful at ranking individuals within the population. Nevertheless, the biases between 431 techniques demonstrate problems in categorising with precision whether a specific individual has 432 crossed the threshold for underweight, overweight, or obesity. If future standardisation could 433 reduce the between-subject variability in this bias, for example through greater standardisation of 434 posture, etc., it could be possible to introduce correction factors removing the average bias. 435 Further work will be necessary to test this in greater detail.

\section{5. Conclusion}

437 We can confirm other validation studies in that the scans generally showed good feasibility, 438 reliability, and validity when used to perform a large number of measurements from a larger number of probands in a short time. On the one hand, scanned and manually measured anthropometric data are highly correlated, but - on the other hand - there also exist important systematic differences due to the nature of the techniques (contact vs. non-contact; different body positions). Thus, the two techniques are not directly equivalent, which makes the direct comparison between averages (e.g., to show time trends) from different techniques impossible without developing correction factors. Nevertheless, the non-invasive and fast character, the low potential for measurement errors, the high reproducibility, and the potential to reassess the archived virtual bodies - even years later by improved software or new algorithms -, make the technique attractive for application in an epidemiological setting.

In order to improve the acceptance of the scan technique, further studies should develop a universally accepted standard scan measurement protocol (focussing on posture, breathing position, etc.), precisely assess the systematic bias between the techniques and its causes in larger samples or metastudies (in particular also for height), address the impact of reclassification among OW/OB risk groups, apply the scanner in follow-up studies to trace body shape changes

453 of an individual over time, and also to optimise the software algorithms in order to correct for the 454 systematic differences between techniques as well as to develop new body shape models or 
455 indicators that are even more closely related to health outcomes than the standard anthropometric 456 approaches in use. 


\section{Acknowledgements}

458 The authors wish to thank: Armasuisse for providing their 3D Scanliner; Andreas Stier, and

459 Thomas Mathis (from Armasuisse) for their technical and scan measurement support; Lena

460 Öhrström, Karl Link, Roger Seiler, and Joël Floris (all IEM, University of Zurich) for their

461 manual measurement assistance; Karl Rüesch, Ralph Stöber, and René Zimmermann (from the

462 University of Zurich) for their technical support; Helga Gäbel (Human Solutions GmbH,

463 Kaiserslautern, Germany), Tobias Pischon (MDC, Berlin), Dörte Radke (Greifswald University),

464 Peter Ahnert (Leipzig University), Peter Jüni (University of Toronto), and Barry Bogin

465 (Loughborough University) for helpful comments. 
466 Table 1: Descriptive statistics of the study group ( $\mathrm{N}=123$, all men) assessed by a questionnaire 467 prior to the measurements. Weight was separately measured in parallel to the scan and manual 468 measurements, $\mathrm{N}=1$ weight measurement was missing. Height and BMI are reported in Tables 2 469 and 3.

\begin{tabular}{|c|c|c|c|c|c|c|c|}
\hline & $\begin{array}{l}\text { Mean } \\
\text { (SD) }\end{array}$ & Min & Max & $\mathbf{N}$ & Categories & Freq. & $\%$ \\
\hline Weight (kg) & $\begin{array}{l}73.96 \\
(9.47)\end{array}$ & 55.5 & 98.3 & 122 & & & \\
\hline \multirow{6}{*}{ Age (years) } & \multirow{6}{*}{$\begin{array}{l}24.55 \\
(4.18)\end{array}$} & \multirow{6}{*}{18} & \multirow{6}{*}{38} & \multirow{6}{*}{123} & Not reported & 2 & 1.6 \\
\hline & & & & & $15-19$ & 5 & 4.1 \\
\hline & & & & & $20-24$ & 69 & 56.1 \\
\hline & & & & & $25-29$ & 32 & 26.0 \\
\hline & & & & & $30-34$ & 12 & 9.8 \\
\hline & & & & & $35-40$ & 3 & 2.4 \\
\hline \multirow{5}{*}{ Weekly hours of sports } & \multirow{5}{*}{$\begin{array}{l}4.2 \\
(3.0)\end{array}$} & \multirow{5}{*}{0} & \multirow{5}{*}{17} & \multirow{5}{*}{123} & $0.0-0.5$ & 7 & 5.7 \\
\hline & & & & & $0.6-2.4$ & 35 & 28.5 \\
\hline & & & & & $2.5-4.9$ & 37 & 30.1 \\
\hline & & & & & $5.0-7.4$ & 30 & 24.4 \\
\hline & & & & & $>=7.5$ & 14 & 11.4 \\
\hline \multirow{4}{*}{$\begin{array}{l}\text { Numbers of visits } \\
\text { to a physician } \\
\text { during the last year }\end{array}$} & \multirow{4}{*}{$\begin{array}{c}1.78 \\
(0.82)\end{array}$} & \multirow{4}{*}{1} & \multirow{4}{*}{5} & \multirow{4}{*}{123} & 1 & 51 & 41.5 \\
\hline & & & & & 2 & 53 & 43.1 \\
\hline & & & & & 3 & 15 & 12.2 \\
\hline & & & & & $>=4$ & 4 & 3.3 \\
\hline
\end{tabular}


470 Table 2: Agreement within methods. Reliability tests in-between the two scan measurements

471 (scans, SM1 and SM2, N=123) and in-between the two manual measurements (tape

472 measurements, MM1 and MM2, N=122).

\begin{tabular}{|c|c|c|c|c|c|c|}
\hline \multicolumn{7}{|c|}{ Scan Measurement (SM) } \\
\hline $\begin{array}{l}\text { Measure } \\
(\mathrm{cm})\end{array}$ & $\begin{array}{l}\text { SM1 } \\
\text { (SD) }\end{array}$ & $\begin{array}{l}\text { SM2 } \\
\text { (SD) }\end{array}$ & $\begin{array}{l}\text { SM1-SM2 } \\
\text { (SD) }\end{array}$ & ICC $(95 \%$ CI $)$ & $\begin{array}{l}\text { Precision } \\
\text { (cm) }\end{array}$ & $\begin{array}{l}\text { Sig. paired } \\
\text { t-test (p) }\end{array}$ \\
\hline Height & $\begin{array}{l}178.29 \\
(6.54)\end{array}$ & $\begin{array}{l}178.33 \\
(6.50)\end{array}$ & $\begin{array}{l}-0.04 \\
(0.55)\end{array}$ & $0.998(0.997-0.999)$ & 0.45 & 0.413 \\
\hline Chest & $\begin{array}{l}97.67 \\
(6.48) \\
\end{array}$ & $\begin{array}{l}97.56 \\
(6.57) \\
\end{array}$ & $\begin{array}{l}0.11 \\
(1.78) \\
\end{array}$ & $0.981(0.973-0.987)$ & 1.24 & 0.486 \\
\hline Waist & $\begin{array}{l}81.42 \\
(6.86)\end{array}$ & $\begin{array}{l}81.34 \\
(6.90)\end{array}$ & $\begin{array}{l}0.09 \\
(1.16)\end{array}$ & $0.993(0.990-0.995)$ & 0.98 & 0.397 \\
\hline Buttock & $\begin{array}{l}97.28 \\
(5.39)\end{array}$ & $\begin{array}{l}97.17 \\
(5.45)\end{array}$ & $\begin{array}{l}0.11 \\
(0.60) \\
\end{array}$ & $0.997(0.995-0.998)$ & 1.18 & 0.052 \\
\hline Hip & $\begin{array}{l}99.19 \\
(5.74)\end{array}$ & $\begin{array}{l}99.11 \\
(5.87)\end{array}$ & $\begin{array}{l}0.09 \\
(0.89)\end{array}$ & $0.994(0.992-0.996)$ & 1.05 & 0.280 \\
\hline \multicolumn{7}{|c|}{ Manual Measurement (MM) } \\
\hline $\begin{array}{l}\text { Measure } \\
(\mathrm{cm})\end{array}$ & $\begin{array}{l}\text { MM1 } \\
\text { (SD) } \\
\end{array}$ & $\begin{array}{l}\text { MM2 } \\
\text { (SD) } \\
\end{array}$ & $\begin{array}{l}\text { MM1-MM2 } \\
\text { (SD) }\end{array}$ & ICC $(95 \% \mathrm{CI})$ & $\begin{array}{l}\text { Precision } \\
(\mathrm{cm})\end{array}$ & $\begin{array}{l}\text { Sig. paired } \\
\text { t-test (p) }\end{array}$ \\
\hline Height & $\begin{array}{l}180.34 \\
(6.56) \\
\end{array}$ & $\begin{array}{l}180.29 \\
(6.53) \\
\end{array}$ & $\begin{array}{l}0.05 \\
(0.42) \\
\end{array}$ & $0.999(0.999-0.999)$ & 0.50 & 0.235 \\
\hline Chest & $\begin{array}{l}93.44 \\
(6.19) \\
\end{array}$ & $\begin{array}{l}94.19 \\
(5.95) \\
\end{array}$ & $\begin{array}{l}-0.75 \\
(2.01) \\
\end{array}$ & $0.968(0.948-0.980)$ & 8.19 & $<0.001$ \\
\hline Waist & $\begin{array}{l}80.11 \\
(6.12) \\
\end{array}$ & $\begin{array}{l}80.50 \\
(6.16) \\
\end{array}$ & $\begin{array}{l}-0.40 \\
(1.19) \\
\end{array}$ & $0.990(0.984-0.993)$ & 4.36 & $<0.001$ \\
\hline Buttock & $\begin{array}{l}84.30 \\
(7.05) \\
\end{array}$ & $\begin{array}{l}84.92 \\
(6.99) \\
\end{array}$ & $\begin{array}{l}-0.62 \\
(2.87)\end{array}$ & $0.955(0.935-0.969)$ & 6.84 & 0.018 \\
\hline Hip & $\begin{array}{l}94.67 \\
(5.73)\end{array}$ & $\begin{array}{l}94.90 \\
(5.68)\end{array}$ & $\begin{array}{l}-0.23 \\
(1.88)\end{array}$ & $0.972(0.960-0.980)$ & 2.50 & 0.186 \\
\hline
\end{tabular}


473 Table 3: Agreement and differences between the two methods when comparing the mean of the 474 two scan measurements ( $\mathrm{mSM}, \mathrm{N}=123)$ and mean of the two manual measurements (mMM, $475 \mathrm{~N}=122) . \mathrm{CCC}=$ Concordance Correlation Coefficient $\left(\mathrm{CCC}=\mathrm{r} * \mathrm{C} \_\mathrm{b}\right)$.

\begin{tabular}{|c|c|c|c|c|c|c|c|}
\hline $\begin{array}{l}\text { Measure } \\
\text { (cm) }\end{array}$ & $\begin{array}{l}\text { mSM } \\
\text { (SD) }\end{array}$ & $\begin{array}{l}\text { mMM } \\
\text { (SD) }\end{array}$ & $\begin{array}{l}\text { mSM- } \\
\text { mMM } \\
\text { (SD) }\end{array}$ & $\begin{array}{l}\text { Sig. paired } \\
\text { t-test (p) }\end{array}$ & $\mathrm{CCC}$ & $\begin{array}{l}\text { Correlatio } \\
\text { n (r) }\end{array}$ & C_b \\
\hline Height & $\begin{array}{l}178.31 \\
(6.51)\end{array}$ & $\begin{array}{l}180.32 \\
(6.54)\end{array}$ & $\begin{array}{l}-2.01 \\
(0.77)\end{array}$ & $<0.001$ & 0.948 & 0.993 & 0.955 \\
\hline Chest & $\begin{array}{l}97.62 \\
(6.47)\end{array}$ & $\begin{array}{l}93.82 \\
(5.98)\end{array}$ & $\begin{array}{l}3.88 \\
(2.17)\end{array}$ & $<0.001$ & 0.784 & 0.941 & 0.833 \\
\hline Waist (WC) & $\begin{array}{l}81.38 \\
(6.86)\end{array}$ & $\begin{array}{l}80.31 \\
(6.11)\end{array}$ & $\begin{array}{l}1.17 \\
(0.13)\end{array}$ & $<0.001$ & 0.960 & 0.982 & 0.978 \\
\hline Buttock & $\begin{array}{l}97.23 \\
(5.41)\end{array}$ & $\begin{array}{l}84.61 \\
(6.87)\end{array}$ & $\begin{array}{l}12.62 \\
(0.35)\end{array}$ & $<0.001$ & 0.258 & 0.828 & 0.312 \\
\hline Hip & $\begin{array}{l}99.19 \\
(5.79)\end{array}$ & $\begin{array}{l}94.77 \\
(5.62)\end{array}$ & $\begin{array}{l}4.37 \\
(0.19)\end{array}$ & $<0.001$ & 0.718 & 0.933 & 0.769 \\
\hline Index & $\begin{array}{l}\text { mSM } \\
\text { (SD) }\end{array}$ & $\begin{array}{l}\mathrm{mMM} \\
\text { (SD) }\end{array}$ & $\begin{array}{l}\text { mSM- } \\
\text { mMM } \\
\text { (SD) }\end{array}$ & $\begin{array}{l}\text { Sig. paired } \\
\text { t-test (p) }\end{array}$ & $\mathrm{CCC}$ & $\begin{array}{l}\text { Correlatio } \\
\text { n (r) }\end{array}$ & C_b \\
\hline WHR & $\begin{array}{l}0.82 \\
(0.04)\end{array}$ & $\begin{array}{l}0.85 \\
(0.03)\end{array}$ & $\begin{array}{l}-0.03 \\
(0.002)\end{array}$ & $<0.001$ & 0.673 & 0.857 & 0.786 \\
\hline WHtR & $\begin{array}{l}0.46 \\
(0.04)\end{array}$ & $\begin{array}{l}0.45 \\
(0.03)\end{array}$ & $\begin{array}{l}0.01 \\
(0.001)\end{array}$ & $<0.001$ & 0.920 & 0.979 & 0.939 \\
\hline $\begin{array}{l}\text { BMI } \\
(\mathrm{kg} / \mathrm{m} 2)\end{array}$ & $\begin{array}{l}23.23 \\
(2.44)\end{array}$ & $\begin{array}{l}22.72 \\
(2.38)\end{array}$ & $\begin{array}{l}0.52 \\
(0.210)\end{array}$ & $<0.001$ & 0.974 & 0.996 & 0.977 \\
\hline
\end{tabular}


476 Table 4: Differences between the two methods (mSM vs. mMM) for WHR, WHtR, and BMI

477 when comparing the prevalence for OW/OB according to the official WHO-categories.

\begin{tabular}{|c|c|c|c|c|c|c|}
\hline & mSM & & $\mathbf{m M M}$ & & $\begin{array}{l}\text { Reclassification } \\
\text { mSM-mMM }\end{array}$ & Kappa \\
\hline $\begin{array}{l}\text { WC } \\
\text { (cm) }\end{array}$ & Freq. & $\%$ & Freq. & $\%$ & & 0.60 \\
\hline$<94.0$ & 114 & 92.7 & 118 & 95.9 & -3.2 & \\
\hline $\begin{array}{l}94.0- \\
101.0\end{array}$ & 9 & 7.3 & 4 & 3.3 & 4.0 & \\
\hline$\geq 102.0$ & 0 & 0.0 & 0 & 0.0 & 0.0 & \\
\hline WHR & Freq. & $\%$ & Freq. & $\%$ & & 0.87 \\
\hline$<0.9$ & 116 & 94.3 & 113 & 91.9 & 2.4 & \\
\hline$\geq 0.9$ & 7 & 5.7 & 9 & 7.3 & -1.6 & \\
\hline$\geq 1.0$ & 0 & 0.0 & 0 & 0.0 & 0.0 & \\
\hline WHtR & Freq. & $\%$ & Freq. & $\%$ & & 0.58 \\
\hline$<0.5$ & 105 & 85.4 & 110 & 89.4 & -4.0 & \\
\hline$\geq 0.5$ & 18 & 14.6 & 12 & 9.8 & 4.8 & \\
\hline $\begin{array}{l}\text { BMI } \\
(\mathrm{kg} / \mathrm{m} 2)\end{array}$ & Freq. & $\%$ & Freq. & $\%$ & & 0.76 \\
\hline$<18.5$ & 2 & 1.6 & 3 & 2.4 & -0.8 & \\
\hline $\begin{array}{l}18.5- \\
24.9\end{array}$ & 92 & 74.8 & 100 & 81.3 & -6.5 & \\
\hline $\begin{array}{l}25.0- \\
29.9\end{array}$ & 28 & 22.8 & 19 & 15.4 & 7.4 & \\
\hline$\geq 30.0$ & 0 & 0.0 & 0 & 0.0 & 0.0 & \\
\hline
\end{tabular}


478 Figure 1: Raw scan outputs of five selected test subjects showing the full range of observed body

479 shapes. Subject A was the thinnest (scanned BMI=16.85kg/m2) and subject E was the heaviest

$480(\mathrm{BMI}=29.48 \mathrm{~kg} / \mathrm{m} 2)$. Subject B represented the "healthy" body shape type with a BMI of

$48120.95 \mathrm{~kg} / \mathrm{m} 2$. Subjects C and D had a similar BMI (27.94 vs. $27.73 \mathrm{~kg} / \mathrm{m} 2)$, but in contrast to

482 subject C, subject D represented the athletic body shape type (reporting 17 hours of sport per

483 week). The faces of the subjects have been pixelated and anonymised.

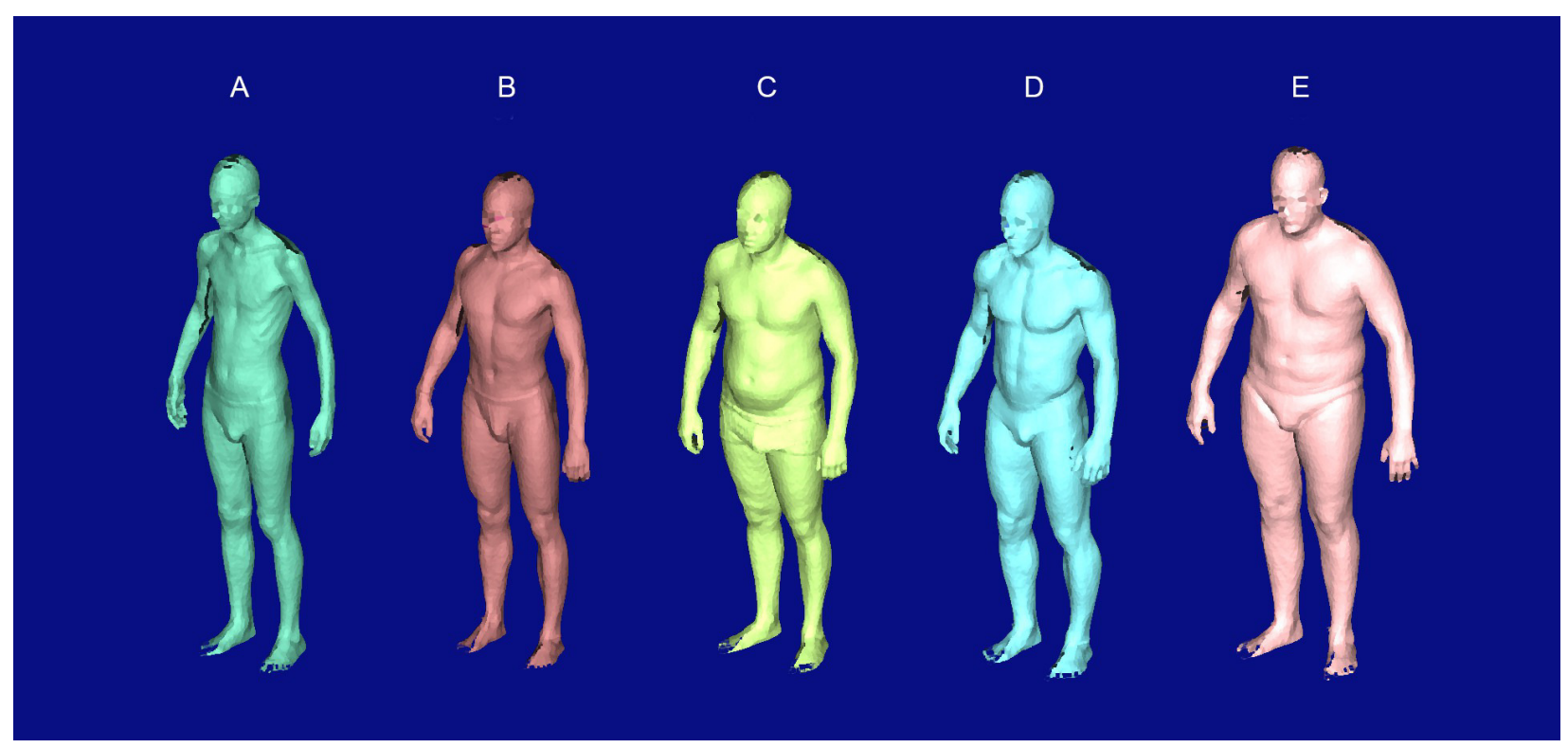


484 Figure 2: Agreement between methods: mSM vs. mMM by scatterplots, kernel density plots 485 (band width = 3), and BA plots: [A] height, [B] chest, [C] waist, [D] buttock, and [E] hip. The 486 detailed results are displayed in Table 3 (buttock: The scanner measured the largest circumference 487 around the buttock, the manual measurers measured the circumference on the mid-buttock 488 position).
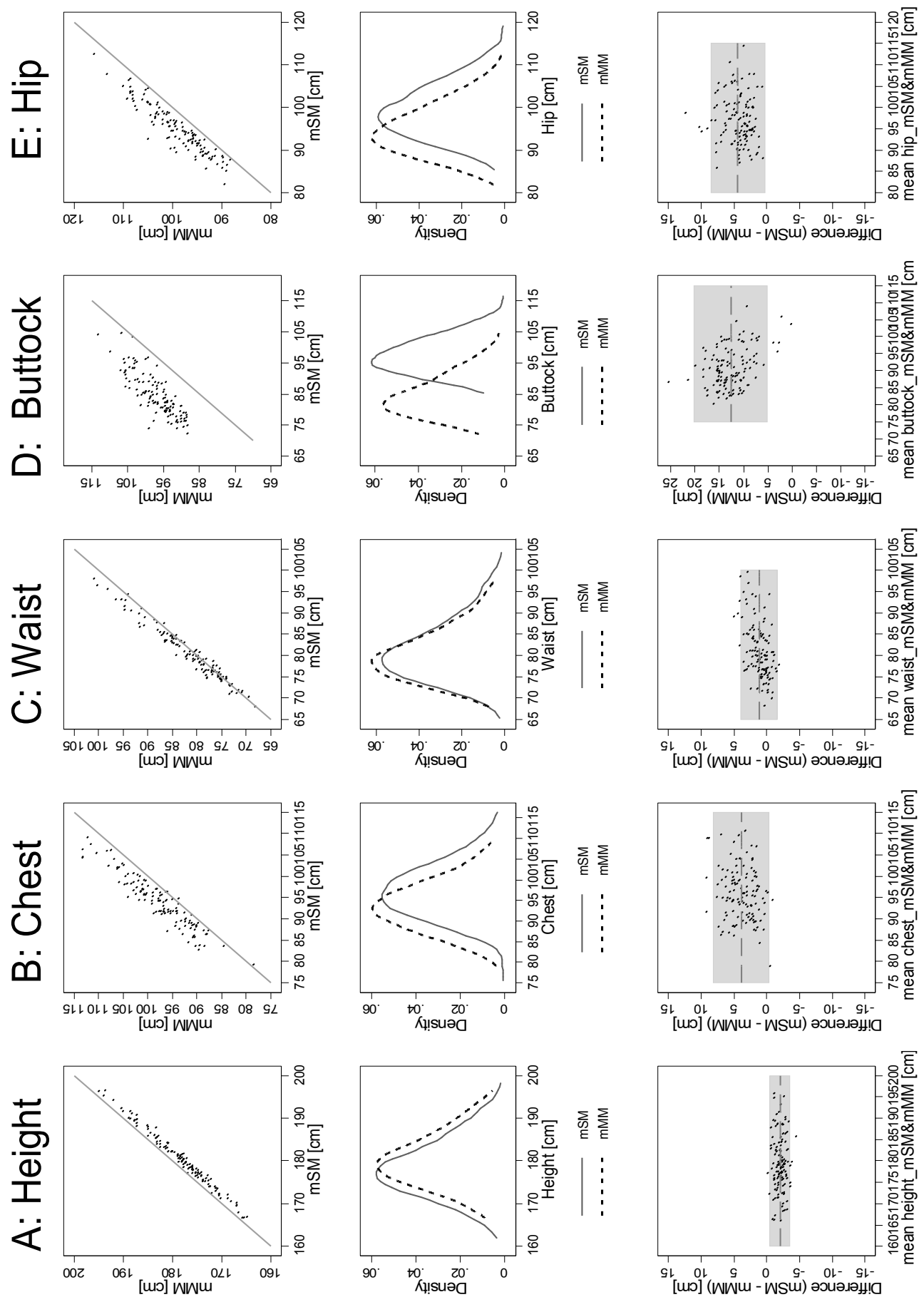
489 Figure 3: Comparison between methods performing linear regressions (and 95\% confidence 490 intervals) showing the association between [A] WHR, [B] WHtR, [C] WC, and [D] BMI (all 491 measured by $\mathrm{mSM}$ as well as $\mathrm{mMM}$ ) with hours of sports per week, number of visits to a 492 physician during the last year, and age $(\mathrm{N}=119$, the detailed results are displayed in Appendix 493 Table 1).
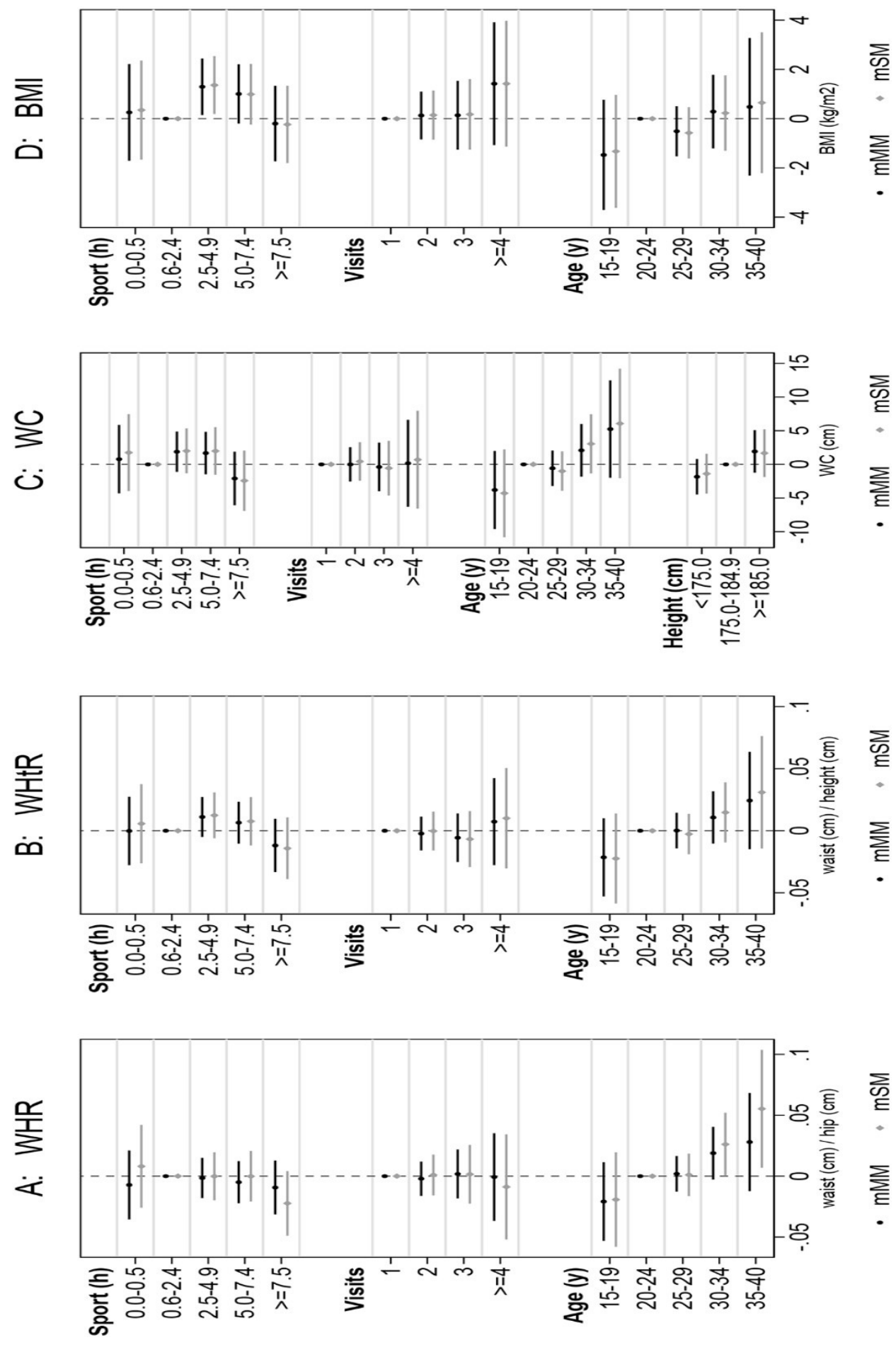
494 Appendix

495 See supplementary files.

496 Appendix Table 1: Comparison between methods performing linear regressions showing the 497 association between WHR, WHtR, WC, and BMI (as measured by mSM and mMM) and hours of 498 sports per week, number of visits to a physician during the last year, and age (coefficients are 499 plotted in Figure 3).

500 Appendix Figure 1: Agreement between the repeated scan measurements (SM1 and SM2) by 501 scatterplots (top row), kernel density plots (middle row, bandwidth $=3$ ), and BA plots (bottom 502 row). The detailed results are displayed in Table 3.

503 Appendix Figure 2: Agreement between the repeated manual measurements (MM1 and MM2)

504 by scatterplots (top row), kernel density plots (middle row, bandwidth $=3$ ), BA plots (bottom 505 row). The detailed results are displayed in Table 3. 


\section{References}

507

508

509

510

511

512

513

514

515

516

517

518

519

520

521

522

523

524

525

526

527

528

529

530

531

532

533

534

535

536

537

538

539

540

541

542

543

544

545

546

547

548

549

550

551

552

553

Altman DG. 1999. Practical statistics for medical research. Chapman \& Hall/CRC: Boca Raton, Fla.

Ashwell M, and Hsieh SD. 2005. Six reasons why the waist-to-height ratio is a rapid and effective global indicator for health risks of obesity and how its use could simplify the international public health message on obesity. International Journal of Food Sciences and Nutrition 56: 303-07.

Bland J, and Altman D. 1986. Statistical methods for assessing agreement between two methods of clinical measurement. Lancet 1: 307-10.

- - . 1999. Measuring agreement in method comparison studies. Statistical Methods in Medical Research 8: 135-60.

Bogin B. 1999. Patterns of human growth.

Bretschneider T, Koop U, Schreiner V, Wenck H, and Jaspers S. 2009. Validation of the body scanner as a measuring tool for a rapid quantification of body shape. Skin Research and Technology: 364-69.

Choi S, and Ashdown SP. 2011. 3D body scan analysis of dimensional change in lower body measurements for active body positions. Textile Research Journal 81: 81-93.

Daniell N, Olds T, and Tomkinson G. 2012. Technical note: Criterion validity of whole body surface area equations: a comparison using 3D laser scanning. American Journal of Physical Anthropology 148: 148-55.

Davin C, Vollenweider P, Waeber G, Paccaud F, and Marques-Vidal P. 2012. Cardiovascular risk factors attributable to obesity and overweight in Switzerland. Nutrition, Metabolism and Cardiovascular Diseases 22: 952-58.

Engeland A, Bjørge T, Selmer RM, Tverdal A, Bjorge T, Selmer RM, Tverdal A, Bjørge T, Selmer RM, and Tverdal A. 2003. Height and body mass index in relation to total mortality. Epidemiology (Cambridge, Mass.) 14: 293-99.

Faeh D, Braun J, and Bopp M. 2012. Body mass index vs cholesterol in cardiovascular disease risk prediction models. Archives of Internal Medicine 172: 1766-8.

Finucane MM, Stevens GA, Cowan MJ, Danaei G, Lin JK, Paciorek CJ, Singh GM, Gutierrez HR, Lu Y, Bahalim AN, Farzadfar F, Riley LM, and Ezzati M. 2011. National, regional, and global trends in body-mass index since 1980: systematic analysis of health examination surveys and epidemiological studies with 960 country-years and 9.1 million participants. Lancet 377: 557-67.

Flegal K, Kit B, Orpana H, and Graubard B. 2013. Association of All-Cause Mortality With Overweight and Obesity Using Standard Body Mass Index Categories: A Systematic Review and Meta-analysis. JAMA The Journal of the American medical Association 309: 71-82.

Gibson RS. 2005. Principles of nutritional assessment. Oxford University Press: New York.

Gracia-Marco L, Moreno LA, Ruiz JR, Ortega FB, de Moraes AC, Gottrand F, Roccaldo R, Marcos A, GomezMartinez S, Dallongeville J, Kafatos A, Molnar D, Bueno G, de Henauw S, Widhalm K, and Wells JC. 2016. Body Composition Indices and Single and Clustered Cardiovascular Disease Risk Factors in Adolescents: Providing Clinical-Based Cut-Points. Progress in Cardiovascular Diseases 58: 555-64.

Han H, Nam Y, and Choi K. 2010. Comparative analysis of 3D body scan measurements and manual measurements of size Korea adult females. International Journal of Industrial Ergonomics 40: 530-40.

Heuberger R, Domina T, and MacGillivray M. 2008. Body scanning as a new anthropometric measurement tool for health-risk assessment. International Journal of Consumer Studies 32: 34-40.

Higgins PBC, A.G. 2012. Measures of Waist Circumference. In: Preedy VR, ed., Handbook of anthropometry : physical measures of human form in health and disease. Springer: New York. ISO. 2005. 'Standards Catalogue'.

Jaeschke L, Steinbrecher A, and Pischon T. 2015. Measurement of waist and hip circumference with a body surface scanner: feasibility, validity, reliability, and correlations with markers of the metabolic syndrome. PLoS One 10: e0119430. 
554

555

556

557

558

559

560

561

562

563

564

565

566

567

568

569

570

571

572

573

574

575

576

577

578

579

580

581

582

583

584

585

586

587

588

589

590

591

592

593

594

595

596

597

598

599

600

601

602
Keys A, Fidanza F, Karvonen MJ, Kimura N, and Taylor HL. 1972. Indices of relative weight and obesity. Journal of chronic diseases 25: 329-43.

Kit BK, Ogden CL, and Flegal KM. 2014. Epidemiology of Obesity. In Handbook of Epidemiology, In: Ahrens W and Pigeot I, ed., 2229-62. New York: Springer Science+Business Media.

Kuehnapfel A, Ahnert P, Loeffler M, Broda A, and Scholz M. 2016. Reliability of 3D laser-based anthropometry and comparison with classical anthropometry. Scientific Reports 6: 26672.

Lee J, Freeland-Graves J, Pepper M, Stanforth P, and Xu B. 2015a. Prediction of Android and Gynoid Body Adiposity via a Three-dimensional Stereovision Body Imaging System and Dual-Energy X-ray Absorptiometry. Journal of the American College of Nutrition 34: 367-77.

Lee J, Freeland-Graves J, Pepper M, Yu W, and Xu B. 2015b. Efficacy of thigh volume ratios assessed via stereovision body imaging as a predictor of visceral adipose tissue measured by magnetic resonance imaging. American Journal of Human Biology 27: 445-57.

Lee SY, and Gallagher D. 2008. Assessment methods in human body composition. Current Opinion in Clinical Nutrition and Metabolic Care 11: 566-72.

Lin JD, Chiou WK, Weng HF, Fang JT, and Liu TH. 2004. Application of three-dimensional body scanner: observation of prevalence of metabolic syndrome. Clinical Nutrition 23: 1313-23.

Lin LI. 1989. A concordance correlation coefficient to evaluate reproducibility. Biometrics 45: 255-68.

Loeffler M, Engel C, Ahnert P, Alfermann D, Arelin K, Baber R, Beutner F, Binder H, Brahler E, Burkhardt R, Ceglarek U, Enzenbach C, Fuchs M, Glaesmer H, Girlich F, Hagendorff A, Hantzsch M, Hegerl U, Henger S, Hensch T, Hinz A, Holzendorf V, Husser D, Kersting A, Kiel A, Kirsten T, Kratzsch J, Krohn K, Luck T, Melzer S, Netto J, Nuchter M, Raschpichler M, Rauscher FG, Riedel-Heller SG, Sander C, Scholz M, Schonknecht P, Schroeter ML, Simon JC, Speer R, Staker J, Stein R, Stobel-Richter Y, Stumvoll M, Tarnok A, Teren A, Teupser D, Then FS, Tonjes A, Treudler R, Villringer A, Weissgerber A, Wiedemann P, Zachariae S, Wirkner K, and Thiery J. 2015. The LIFE-Adult-Study: objectives and design of a population-based cohort study with 10,000 deeply phenotyped adults in Germany. BMC Public Health 15: 691.

Machann J, Thamer C, Schnoedt B, Haap M, Haring HU, Claussen CD, Stumvoll M, Fritsche A, and Schick F. 2005. Standardized assessment of whole body adipose tissue topography by MRI. Journal of Magnetic Resonance Imaging 21: 455-62.

Malatesta D. 2013. Gültigkeit und Relevanz des Body-Mass-Index (BMI) als Massgrösse für Übergewicht und Gesundheitszustand auf individueller und epidemiologischer Ebene. In Gesundheitsförderung Schweiz, In: ed.

Marques-Vidal P, Bochud M, Mooser V, Paccaud F, Waeber G, and Vollenweider P. 2008. Prevalence of obesity and abdominal obesity in the Lausanne population. BMC Public Health 8: 330.

Mason C, and Katzmarzyk P. 2009. Variability in waist circumference measurements according to anatomic measurement site. Obesity (Silver Spring) 17: 1789-95.

McKinnon L, and Istook C. 2002. Body scanning: The effects of subject respiration and foot positioning on the data integrity of scanned measurements. Journal of Fashion Marketing and Management. Journal of Fashion Marketing and Management 6: 103-21.

NCD-RisC. 2016. Trends in adult body-mass index in 200 countries from 1975 to 2014: a pooled analysis of 1698 population-based measurement studies with 192 million participants. Lancet 387: 137796.

$\mathrm{Ng}$ BK, Hinton BJ, Fan B, Kanaya AM, and Shepherd JA. 2016. Clinical anthropometrics and body composition from 3D whole-body surface scans. European Journal of Clinical Nutrition 70: 126570.

NHANES. 1988. National Health and Nutrition Examination Survey III. Body Measurements (Anthropometry).

Ogna A, Forni Ogna V, Bochud M, Paccaud F, Gabutti L, Burnier M, and Group SSoS. 2014. Prevalence of obesity and overweight and associated nutritional factors in a population-based Swiss sample: an 
603

604

605

606

607

608

609

610

611

612

613

614

615

616

617

618

619

620

621

622

623

624

625

626

627

628

629

630

631

632

633

634

635

636

637

638

639

640

641

642

643

644

645

646

647

648

649

650

651 opportunity to analyze the impact of three different European cultural root. European Journal of Nutrition 53: 1295.

Olds T, Daniell N, Petkov J, and David Stewart A. 2013. Somatotyping using 3D anthropometry: a cluster analysis. Journal of sports sciences 31: 936-44.

Olivares J, Wang J, Yu W, Pereg V, Weil R, Kovacs B, Gallagher D, and Pi-Sunyer F. 2007. Comparisons of Body Volumes and Dimensions Using Three-Dimensional Photonic Scanning in Adult HispanicAmericans and Caucasian-Americans. Journal of diabetes science and technology (Online) 1: 92128.

Peyer KE, Morris M, and Sellers WI. 2015. Subject-specific body segment parameter estimation using 3D photogrammetry with multiple cameras. PeerJ 3: e831.

Pischon T, Boeing H, Hoffmann K, Bergmann M, Schulze MB, Overvad K, van der Schouw YT, Spencer E, Moons KG, Tjonneland A, Halkjaer J, Jensen MK, Stegger J, Clavel-Chapelon F, Boutron-Ruault MC, Chajes V, Linseisen J, Kaaks R, Trichopoulou A, Trichopoulos D, Bamia C, Sieri S, Palli D, Tumino R, Vineis P, Panico S, Peeters PH, May AM, Bueno-de-Mesquita HB, van Duijnhoven FJ, Hallmans G, Weinehall L, Manjer J, Hedblad B, Lund E, Agudo A, Arriola L, Barricarte A, Navarro C, Martinez C, Quiros JR, Key T, Bingham S, Khaw KT, Boffetta P, Jenab M, Ferrari P, and Riboli E. 2008. General and abdominal adiposity and risk of death in Europe. The New England Journal of Medicine 359: 2105-20.

Preedy V. 2012. Handbook of anthropometry: physical measures of human form in health and disease. Springer: New York.

Psikuta A, Frackiewicz-Kaczmarek J, Mert E, Bueno M, and Rossi R. 2015. Validation of a novel 3D scanning method for determination of the air gap in clothing. Measurement 67: 61-70.

Schmid A, Schneider H, Golay A, and Keller U. 2005. Economic burden of obesity and its comorbidities in Switzerland. Sozial-Und Praventivmedizin 50: 87-94.

Schneider H, Friedrich N, Klotsche J, Pieper L, Nauck M, John U, Dorr M, Felix S, Lehnert H, Pittrow D, Silber S, Volzke H, Stalla G, Wallaschofski H, and Wittchen H. 2010. The predictive value of different measures of obesity for incident cardiovascular events and mortality. The Journal of Clinical Endocrinology \& Metabolism 95: 1777-85.

Schneider H, and Venetz W. 2014. Cost of Obesity in Switzerland in 2012. Final Report. In, In: ed. Rheinfelden $\mathrm{CH}$.

Sebo P, Haller D, Pechère-Bertsch A, Patrick Bovier P, and Herrmann F. 2015. Accuracy of doctors' anthropometric measurements in general practice. Swiss Med Wkly. 2015 145:w14115.

Tomkinson G, and Shaw L. 2013. Quantification of the postural and technical errors in asymptomatic adults using direct 3D whole body scan measurements of standing posture. Gait \& Posture 37: 172-77.

Treleaven P, and Wells J. 2007. 3D body scanning and healthcare applications. Computer 40: 28-+.

Veitch D, Veitch L, and Henneberg M. 2007. Sizing for the Clothing Industry Using Principal Component Analysis - An Australian Example. Journal of American Society for Testing and Materials International (JAI) 4: 1-12.

Verweij L, Terwee C, Proper K, Hulshof C, and van Mechelen W. 2013. Measurement error of waist circumference: gaps in knowledge. Public Health Nutrition 16: 281-88.

Wang J, Gallagher D, Thornton J, Yu W, Horlick M, and Pi-Sunyer F. 2006. Validation of a 3-dimensional photonic scanner for the measurement of body volumes, dimensions, and percentage body fat. American Journal of Clinical Nutrition 83: 809-16.

Wells J. 2012. Three-Dimensional (3-D) Photonic Scanning: A New Approach to Anthropometry. In Handbook of Anthropometry: Physical Measures of Human Form in Health and Disease, In: Preedy VR, ed., 205-17. New York, NY: Springer New York.

Wells J, Cole T, Bruner D, and Treleaven P. 2008. Body shape in American and British adults: betweencountry and inter-ethnic comparisons. Int J Obes (Lond) 32: 152-9. 
652

653

654

655

656

657

658

659

660

661

662

663

664

665
Wells J, Stocks J, Bonner R, Raywood E, Legg S, Lee S, Treleaven P, and Lum S. 2015. Acceptability, Precision and Accuracy of 3D Photonic Scanning for Measurement of Body Shape in a MultiEthnic Sample of Children Aged 5-11 Years: The SLIC Study. Plos One 10.

Wells J, Treleaven P, and Charoensiriwath S. 2011. Body shape by 3-D photonic scanning in Thai and UK adults: comparison of national sizing surveys. International Journal of Obesity (London) 36: 14854.

WHO. 2008. Waist Circumference and Waist-Hip Ratio: Report of a WHO Expert Consultation.

- - . 2009. Global Health Risks: Mortality and Burden of Disease Attributable to Selected Major Risks. In, In: ed.

- - - 2014. BMI classification.

Yusuf S, Hawken S, Ounpuu S, Bautista L, Franzosi MG, Commerford P, Lang CC, Rumboldt Z, Onen CL, Lisheng L, Tanomsup S, Wangai Jr. P, Razak F, Sharma AM, and Anand SS. 2005. Obesity and the risk of myocardial infarction in 27,000 participants from 52 countries: a case-control study. Lancet 366: 1640-49. 